\title{
Mensajes Políticos y Derechos Humanos en los Videojuegos
}

\section{Political Messages and Human Rights in Video Games}

\author{
Autor: \\ Gdo. Jose Antonio Moya Martínez \\ https://orcid.org/0000-0002-6898-0717 \\ moyamartinez.ja@gmail.com \\ Twitter@MararesVA
}

\begin{abstract}
Resumen
El videojuego, en la actualidad, se ha convertido en un medio de comunicación más, con la capacidad de transmitir mensajes e ideas que se refuerzan gracias a su elemento característico, la interactividad. En esta investigación se pretende analizar la capacidad de transmisión de mensajes políticos en el videojuego, explorar la presencia de los derechos humanos dentro de los estudios de caso y, el último objetivo de este texto es apreciar el mensaje subyacente de los videojuegos analizados. Para cumplir los objetivos anteriores se realizará un estudio de caso en el que se emplea una metodología holística introduciendo elementos lúdico-semióticos, socialconstructivistas, estéticos y procedurales. Los principales resultados que se pueden adelantar son que el empleo crítico de este medio permite generar diversas cuestiones sobre el papel de los valores en la política exterior y la vulneración de los derechos en beneficio de una "seguridad" poco definida que parece construida para atacar al "otro".
\end{abstract}

Palabras clave: Giro estético, videolúdico, desinformación, valores, derechos humanos

\section{Abstract}

Today, the video game has become another means of communication, with the ability to transmit messages and ideas that are reinforced thanks to its characteristic element, interactivity. This research aims to analyze the political messages transmission capability in these video games, to explore the presence of the human rights from the case study and, the last aim of this text is to appreciate the underlying message of the analyzed videogames. To meet the above objectives, a case study will be carried out in which a holistic methodology is used, introducing playful-semiotic, social-constructivist, aesthetic and procedural elements. The main results that can be anticipated are that the critical use of this medium allows generating various questions about the role of values in foreign policy and the violation of rights in benefit of a poorly defined "security" that seems built to attack the "other".

KeyWords: Aesthetic turn, videoludic, disinformation, values, human rights 


\section{Introducción}

En el presente artículo se intentará analizar la capacidad del ocio videolúdico como una competencia digital fundamental debido a que puede actuar como un elemento crítico; transmitiendo críticas políticas y concienciando sobre derechos humanos. Es especialmente importante ya que, este ocio se está perfilando como fundamental dentro de la "cultura pop" que es mainstream en la actualidad y, más concretamente, en la juventud, según datos de Newzoo más de un $20 \%$ de los jugadores están comprendidos entre el intervalo 10-20 años (Newzoo, 2021).

La idea de que los videojuegos son un tipo de ocio cada vez más popular es muestra de que estamos inmersos en una sociedad digital y, especialmente, desarrollada en estos últimos años. Prueba de ello es el especial hincapié que los gobiernos hacen, actualmente, en programas para desarrollar la digitalización y, especialmente, aprovechando esta industria para la exportación de sus elementos culturales o narrativas geopolíticas; España a través del Plan de impulso al sector audiovisual (Gobierno de España, 2021), la República Checa, donde a partir de 2024 podrá comenzarse una financiación pública (McEnchroe y Horáček, 2021), Polonia (ICEX, 2019) o Rusia, por citar algunos ejemplos (Ministry of Digital Development, Communications and Mass Media of the Russian Federation [Minkomsvyaz], 2015).

La alfabetización digital, en general, de la población es ya una preocupación política en España (Boletín Oficial del Estado [BOE], 2020: 34). Esto implica que tome relevancia este concepto que podría definirse como fomentar el conocimiento y vocabulario que permita comprender y criticar el rol de la tecnología, donde los dilemas morales están presentes (Usher, 2019: 216-218). Otros autores hablan directamente de alfabetización mediática de manera similar a la digital, salvo que incluyen el análisis de lenguajes, estética y valores (Bordón, 2019: 5).

A los dos conceptos anteriores se debería sumar el de transmedia; "Un conjunto de habilidades, prácticas, valores, sensibilidades y estrategias de aprendizaje e intercambio desarrolladas y aplicadas en el contexto de las nuevas culturas colaborativas" (Scolari, 2018: 4). Este concepto es fundamental debido a que lo videolúdico tiene entre sus características el que es una industria puede favorecer una cultura colaborativa, algo que puede apreciarse con los grupos de modders.

Algo fundamental, por lo que se debe entender al videojuego inserto en lo transmedia, debido a que en muchas ocasiones se nutre de las imágenes generadas desde otros medios, dando lugar a una reproducción y simplificación del mensaje; como indica Sartori. Visible es lo que prima a día de hoy, la imagen es una representación visual simple (1998: 12-35). A su vez, estas imágenes se suelen presentar desprovistas de su contexto en favor del mero espectáculo visual (Venegas, 2018).

Actualmente, el ocio videolúdico está siendo empleado en una multitud de variantes, por ejemplo, en lo referente al campo educativo a todos los niveles; defendiéndose el ocio videolúdico como un medio para llevar a cabo estrategias de gestión y planificación urbana (Rojas, 2017) otro aspecto que ha estudiado los videojuegos es en lo referente a las dinámicas burocráticas y sus implicaciones como en el caso de Papers Please (Moreno, 2021: 
262) o la saga Beholder; el papel del videojuego en la historia (Grupo de Transferencia del Conocimiento Historia y Videojuegos); los valores en la educación secundaria (Moreno y Lago, 2019) o, la problemática internacional a través del papel del periodista (Moreno, 2020; Moreno y Venegas, 2020a).

También se emplea el videojuego para combatir la desinformación, especialmente los newsgames han permitido la publicación de videojuegos ad hoc con el objetivo de prevenir este problema (Elias, 2018; Mainer y Martínez-Fresneda, 2019; Bordón, 2019; Gómez y Carrillo, 2020; González, 2021).

Estos empleos de los videojuegos se deben a que pueden actuar como reflejo de la realidad e interacción social "El videojuego ya no se concibe como un mero entretenimiento individual, sino que gracias al avance de las TICs son posibles dinámicas en la que varios jugadores de distintos puntos del mundo jueguen e interaccionen entre sí" (Moreno y Venegas, 2020a). En el siglo pasado, la televisión modificó la relación entre el ver y entender (Sartori, 1998: 36); sin embargo, a día de hoy, el videojuego trasciende esa relación entre el ver-entender y llega a difuminar al emisor-receptor. Se da lugar a cierta "democratización" que permite el surgimiento de videojuegos indies de carácter crítico dando espacio a narrativas desplazadas.

Aunque esta "democratización", anteriormente mencionada, al igual que el ámbito digital, en general, tiene una doble vertiente, pudiendo ser tanto positiva como negativa. Se debe pensar que existen multitud de buenas iniciativas como, por ejemplo, Global Conflicts: Sweatshops (Serious Games Interactive, 2009) donde se denuncia la explotación infantil en el sudeste asiático pero, no por ello se debe olvidar que es una vía para la plasmación de corrientes de pensamiento peligrosas que emplean estos medios como una plataforma para su contrapoder (Elías, 2018).

Alfabetizarse digitalmente a través de lo videolúdico es fundamental, ya que esto permitirá estar prevenidos a las diferentes formas de apropiación de la contracultura, también estar alerta sobre la interpelación o, la capacidad de confundir las ideas del emisor y emisario (Manovich, 2005: 108-109), algo que se produce a través de la transmisión de las imágenes y mensajes; por ejemplo, de la extrema derecha a través de este medio (Venegas, 2020a). Tanto es así, que se pueden encontrar ejemplos que atacan a cualquier valor y derechos en los que se debe educar a cualquier generación, destacando la igualdad, la justicia, la paz y la dignidad. Por citar un ejemplo, a los que anteriormente se hace mención, se encuentra Karen Simulator: Wagecuck vs Karen (2GenPro, 2020) donde una serie de "mujeres enojadas" han masacrado a los amigos del protagonista y éste deberá masacrarlas (ver imagen 1). Este juego se ha empleado para justificar ataques contra las posiciones feministas o "socialistas" a través de la comunidad que se ha generado (ver imagen 2). 
Imagen 1: Karen Simulator: Wagecuck vs Karen

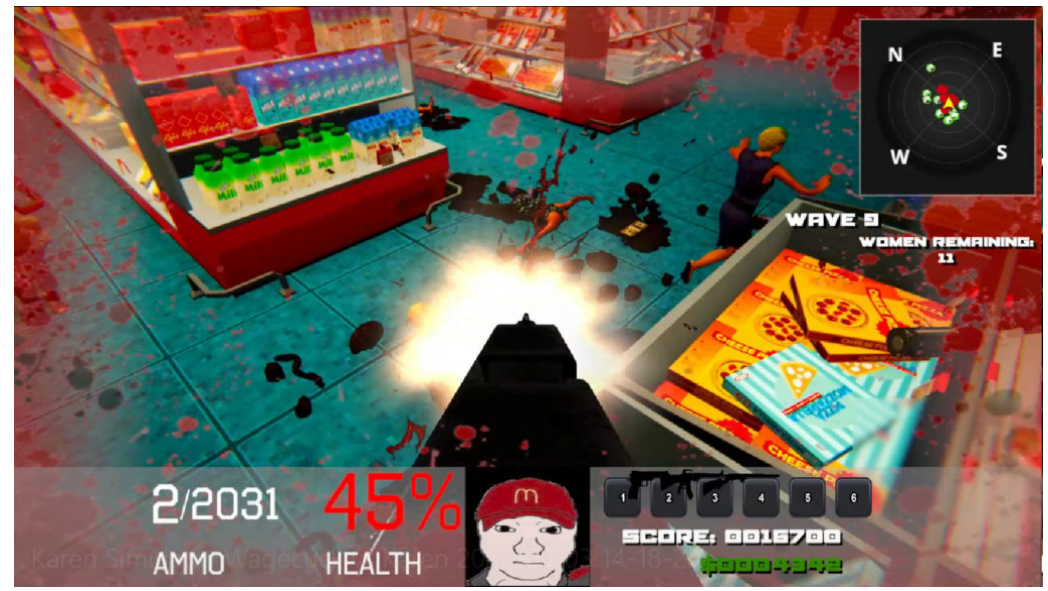

Captura de pantalla de Karen Simulator (2GenPro, 2020)

Imagen 2: Comentario de Karen Simulator: Wagecuck vs Karen

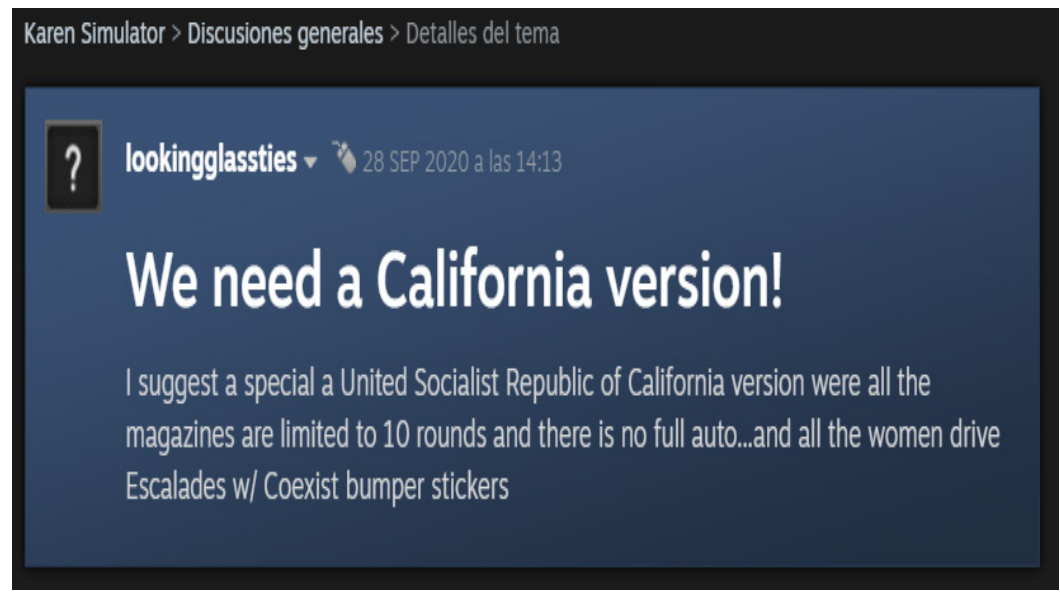

Captura de pantalla a un comentario en Steam, donde se pueden apreciar ataques a una de las regiones más progresistas de los Estados Unidos

Partiendo de este desarrollo previo cabe preguntarse ¿por qué es tan importante introducir competencias de alfabetización en general $\mathrm{y}$, en concreto, a través del videojuego? Para responder a esta pregunta se formula una serie de objetivos de investigación:

En primer lugar, se analizará la capacidad de transmisión de mensajes políticos.

Un segundo objetivo será explorar la presencia de derechos humanos dentro de los estudios de caso. 
El tercer objetivo estará en apreciar el mensaje subyacente (crítica) de los casos analizados.

\section{Metodología}

El realizar un análisis del mensaje y entorno ideológico de un videojuego implica un desafío por su propia naturaleza de simulación "to simulate is to model a (source) system through a different system which maintains (for somebody) some of the behaviors of the original system [...] this model reacts to certain stimuli [...], according to a set of conditions" (Frasca, 2004: 223). Así, como una dificultad añadida es el hecho de que existan diferentes niveles ideológicos con capacidad de plasmar la agenda del diseñador dentro de las propias leyes del juego (Frasca, 2004: 232-233). Es por esto por lo que esta investigación será netamente de carácter cualitativo e interpretativo, todo ello empleado de una manera holística.

En esta investigación se ha optado por emplear una metodología videolúdica-semiótica, ya empleado por otros autores en diversas investigaciones (Pérez, 2012; Méndez, 2019; Galera, 2021). Este análisis permite analizar la dimensión enunciativa, así como la dimensión narrativa a través de las unidades de gameplay representativas del juego y su relación final en la integración del jugador en el eje Sujeto-Entorno. Este elemento es fundamental, ya no solo por la facilidad del análisis estético o la concepción total de los mensajes transmitidos por el juego, sino que es de vital importancia para la consideración de un elemento que no debe ser olvidado: la presencia de elementos afectivos y la integración de estos en la totalidad de la obra. Este análisis, en su parte lúdica destaca por su potencial de significación.

El socialconstructivismo permite establecer un marco manejable de superación de uno de los principales problemas de la simulación presentados por Frasca, la variedad de comportamientos. El principal estudio de caso que se realiza es el videojuego Langley (Pixel Chronicles, 2015) no es casual, ya que su descripción "A lonely man in Afghanistan discovers the true meaning of imperialism" es buena muestra del sentimiento crítico hacia la política exterior estadounidense. Esta descripción, aunque breve, es fundamental al ser una declaración de intenciones: el videojuego está marcado por la preponderancia de las cosmovisiones, las ideas y como el contexto cultural-institucional y la identidad colectiva constituyen factores determinantes en las concepciones de seguridad de los Estados (Ibáñez, 2015: 196-198) así como de los estereotipos que estos pueden servirse.

Otras metodologías, fundamentalmente, necesarias son la textualización propuesta por Shapiro, que podrían encuadrarse dentro del giro estético y la retórica procedural (Bogost, 2007). Respecto al primero, es un marco que permitirá realizar del videojuego un análisis sobre cómo las ideas y representaciones estéticas se transmiten o diferencian de las diferentes cosmovisiones; cómo se dan diferencias entre lo representado y la representación sin olvidar que el representar es un acto de poder capaz de distinguir subjetivamente orígenes y valores (Bleiker, 2001: 510-515). La retórica procedural permite analizar los argumentos que generan los procesos; el cómo las mecánicas del juego afectan a la plasmación de las ideas que el juego transmite.

\section{Resultados}

El videojuego Langley (Pixel Chronicles, 2015) tendría un encaje perfecto para favorecer 
una alfabetización digital con especial hincapié en los valores y derechos humanos.

La actual legislación española, la Ley Orgánica 3/2020, de 29 de diciembre en su artículo 25 hace mención a la obligatoriedad de la "Educación en Valores cívicos y éticos". En esta asignatura se busca generar, entre otros, una reflexión ética y lo referido a los Derechos Humanos, aquí Langley cumple sobradamente debido a su premisa; un ciudadano al que se le vulneran todos los derechos humanos básicos bajo el falso pretexto de la seguridad de un Estado. El escenario básico es una celda y, las interacciones básicas serán diferentes torturas acompañadas de texto; principalmente acusaciones, amenazas e insultos (ver imagen 3).

\section{Imagen 3: el "Buzo" en Langley}

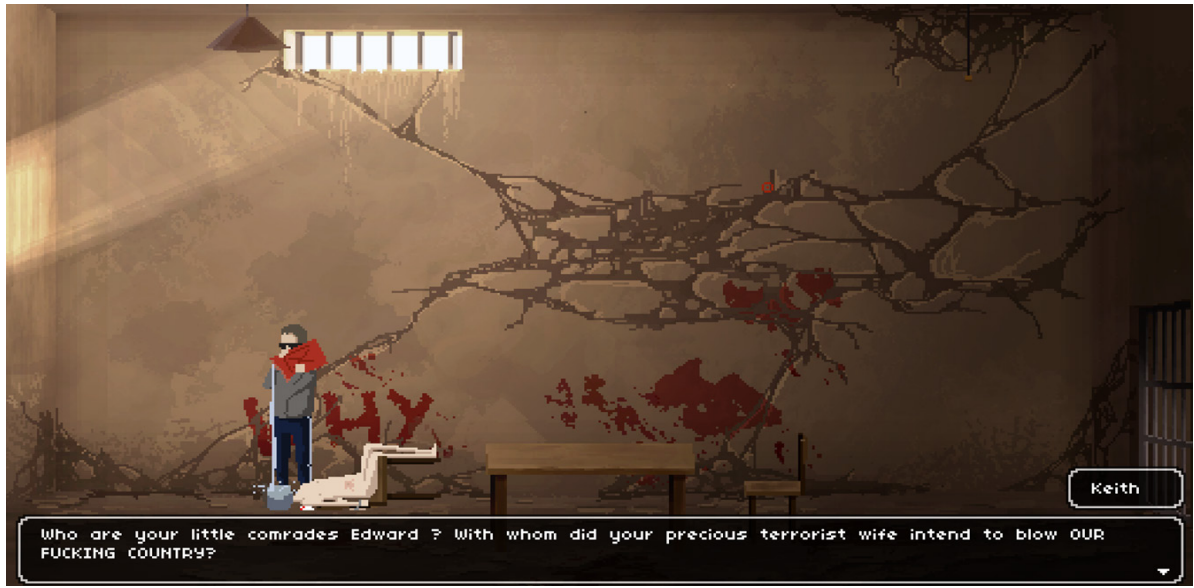

Captura de pantalla propia al videojuego Langley (Pixel Chronicles, 2015)

Este juego se caracteriza por ser una experiencia (de unos 15 minutos) diseñada con el objetivo de criticar la violación de los derechos humanos sin ninguna consideración. El jugador aprende determinados comportamientos como adecuados o idóneos mediante una gameplay rígida, fundamental y acorde con el proceso de asimilación que el jugador debe "sufrir" para introducirse en la estructura de los procesos y reglas. Aquí, la experiencia prototípica del jugador y del sujeto debe entenderse como una experiencia afectiva ya que las reglas de acción/transformación (los modos de hacer) y los procesos de adaptación son similares para el sujeto (avatar-Edward) y jugador (individuo). Se genera un elemento empático y emocional entre ambos.

El diseño del gameplay se basa en formas de redundancia, propio de la definición de las condiciones de victoria y/o derrota; sin dar margen a las formas de variabilidad estructurada, o empleando otros términos, el jugador no tiene margen para establecer ninguna estrategia. Lo anterior, produce que el jugador sufra un tiempo excéntrico; da igual cualquier acción que el jugador intente desarrollar, el gameplay avanzará independientemente; sin ninguna ayuda, lo que refuerza el sentimiento de vulneración de derechos (como el derecho a no ser detenido arbitrariamente). Esta construcción de gameplay deriva en que el juego busca hacer del jugador una persona sumisa; como se puede ver en la imagen 4, solo habrá una respuesta correcta, reconocer que tu mujer planea un ataque contra los EEUU. 


\section{Imagen 4: no hay opción}

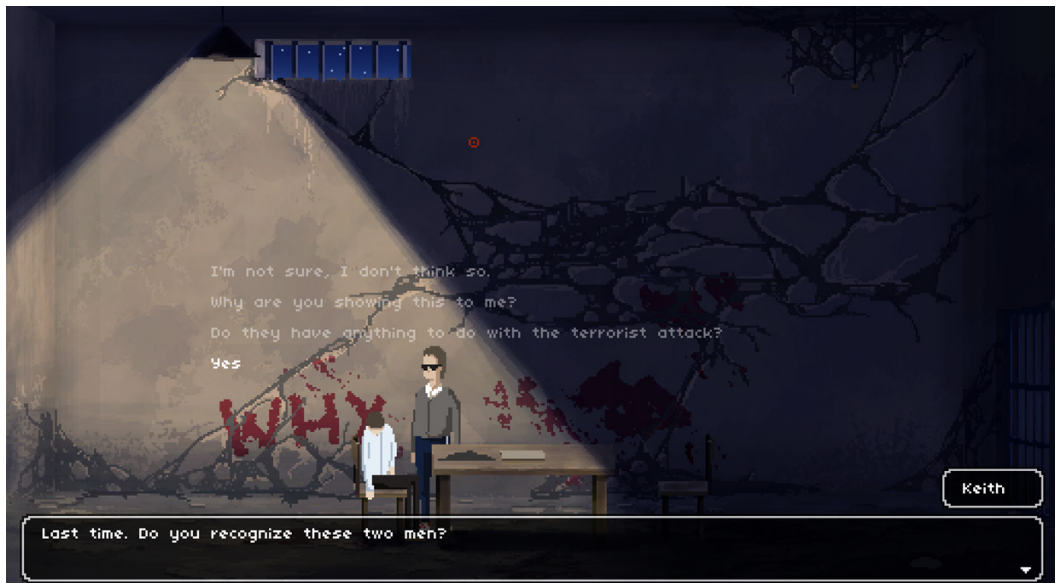

Captura de pantalla propia al videojuego Langley (Pixel Chronicles, 2015)

¿Qué supone este gameplay? Analizando la ideología que el estudio busca transmitir, la agenda que plasman los desarrolladores parece clara, desean preguntarnos hasta qué punto los Estados que se denominan "occidentales" (concretamente los Estados Unidos) son capaces de renunciar a los derechos y principios que ellos mismos promulgan en favor de la "seguridad nacional". Para ello, presentan una vulneración tras otra de diferentes derechos humanos suscritos por estos Estados.

En un primer lugar, parece claro que este juego, estéticamente, parece inspirarse en las prácticas abusivas de cárceles como Abu Ghraib (imagen 5) o de los famosos "sitios negros" de la CIA como Salt Pit; claramente contradicen la narrativa de los diferentes presidentes estadounidenses que legitiman la guerra en la introducción alegando que es una guerra por la libertad, la justicia, las libertades civiles, la ley, e incluso el compromiso con evitar la tortura; donde se vulneraban derechos y libertades humanas fundamentales tales como los artículos 10, 19 o 29 de la declaración fundamental de los derechos humanos; algo que como se ha podido apreciar a lo largo del texto, está presente en el primer nivel de ideología (la narrativa), la manipulación de las reglas (segundo nivel) y en el propio escenario de derrota (tercer nivel) de Langley.

Al avatar lo torturan de manera muy semejante, a nivel estético, a los presos de los lugares de detención clandestinos lo desnudan, usan sondas, les dan múltiples palizas, los encierran en jaulas donde no pueden ni sentarse; se refuerzan negativamente las acciones del jugador, especialmente, cuando se pone al jugador en la falsa dicotomía amor-nacionalismo (algo que busca claramente la empatía del jugador). Falsa debido a que dará igual que se opte por un comportamiento egoísta o generoso, recibirás golpes. Se despoja al jugador de cualquier autonomía simbólica y, por tanto, se establece un diálogo entre el jugador y el desarrollador a través de marcas como la presencia de un personaje prototípico y fácilmente reconocible (el interrogador de la CIA) que puede también encontrarse en otros medios como las series Homeland (Teakwood Lane Studio, 2011) o The Looming Tower (Legendary Television, 2018). 


\section{Imagen 5: Derechos en Abu Ghraib}

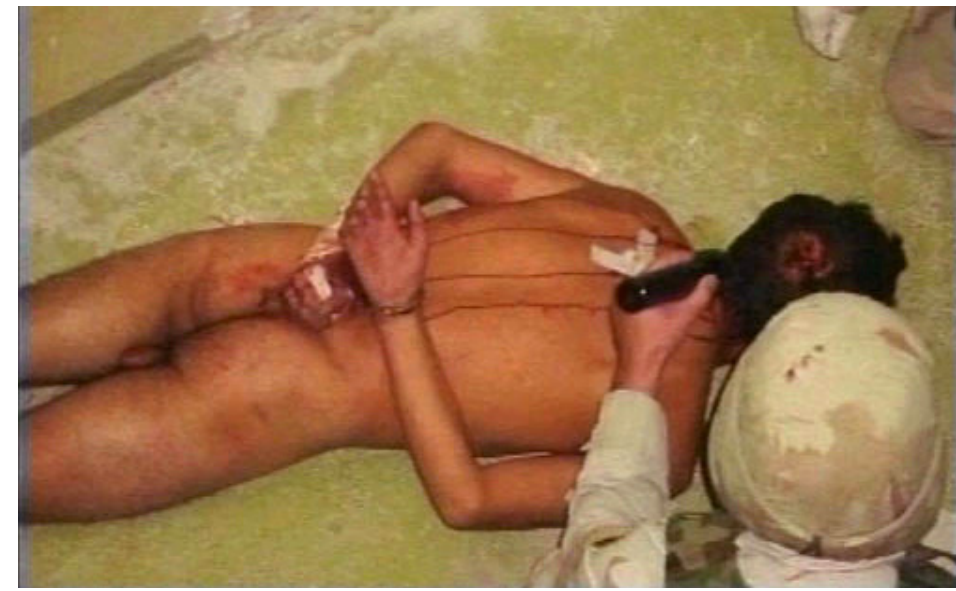

(U.S. Government, 2003)

En relación con las series de televisión citadas no se debe olvidar que la crítica que lleva a cabo el juego (imagen 6) se nutre de estilos y diseños, claramente, reconocibles. Para jugadores se emplea un formato de side-scroller y point and click; mientras que para cualquier persona que no esté familiarizada con el ocio videolúdico encontrará una estética e interrogador (de la $\mathrm{CIA}$ ) prototípicos, fácilmente reconocibles para cualquiera que haya visto una serie donde algún miembro de la CIA interrogue o se piense en la representación visual de una celda. De la narrativa del interrogador pueden extraerse los principios de la cosmología de los "neoconservadores"; el relativismo moral como crítica a la anterior ejecutiva y, especialmente la crítica a no usar la fuerza.

\section{Imagen 6: Reivindicación final}

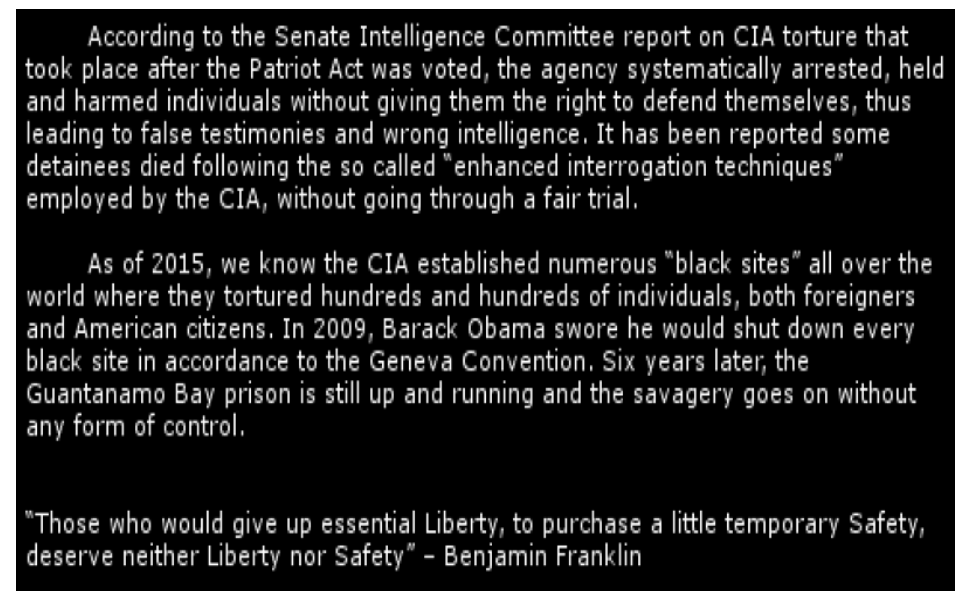

Captura de pantalla Langley (Pixel Chronicles, 2015)

No puede olvidarse el contexto en el que esta obra se basa y es que, aunque el videojuego no hace especial hincapié se puede observar una dinámica post 11-S. El avatar manejado por el jugador es perceptiblemente caucásico (comparte el color de piel de sus secuestradores) y, claramente es un ciudadano estadounidense. En la imagen 3 se puede apreciar 
como se habla en una primera persona del plural para referirse a los Estados Unidos, siendo el país de procedencia por parte del torturador, mientras que en la imagen 6 se alude claramente al hecho de que se torturaron a extranjeros y ciudadanos, poniendo en cuestión de nuevo los derechos civiles. Sin embargo, lo destacable y sobre lo que versa parte del texto y el detonante de la trama es que se intuye que su mujer es de origen palestino; el juego denuncia el racismo anti-árabe que se generó después de los atentados.

En relación con lo anterior, no es baladí que se considere terrorista a una persona, claramente, de un entorno occidental (como se podría apreciar en la estética del color de piel, oficina, vestimenta etc.) en contraposición a donde parece residir y se produce el secuestro; como muestra la imagen 7 la estética es claramente reconocible de algún lugar de oriente medio. Esto es fundamental, ya que el contexto cultural-institucional post 11-S se caracterizó por un pánico de parte de la sociedad que veía amenazada su identidad, algo que se retroalimentó con la concepción de seguridad neoconservadora; las ideas y las creencias condicionaron a la opinión pública mientras que la política exterior neoconservadora la aprovechó para legitimarse, algo que se puede apreciar en el texto del juego a través de la defensa de la fuerza; "El sacrificio de unos pocos puede salvar a muchos".

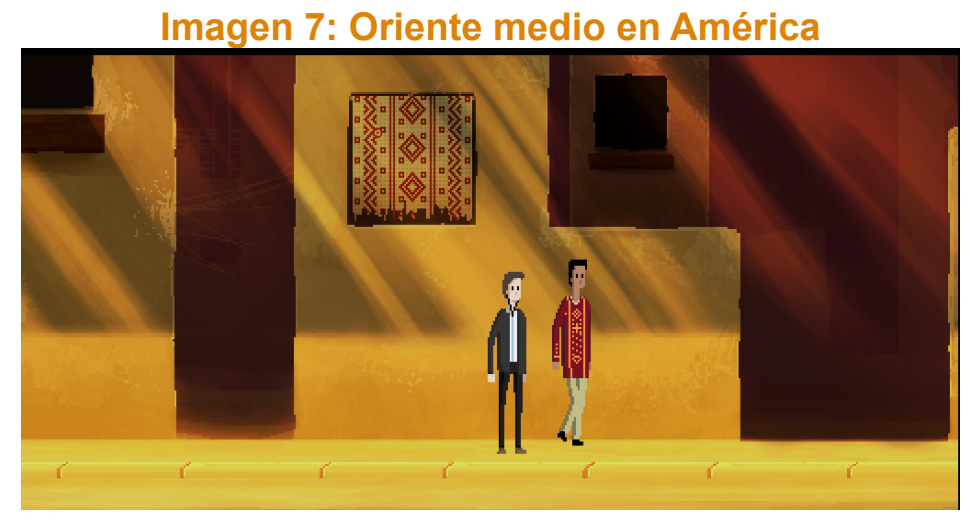

Captura de pantalla Langley (Pixel Chronicles, 2015)

Las mecánicas del juego y el diseño del gameplay refuerzan esta crítica a la idea de la legitimación de la fuerza y, en buena medida, a la islamofobia. El avatar que maneja el jugador es simple y débil tanto como, que solo puede a través de sus mecánicas responder lo exigido y andar; solo podrá recurrir en un momento a la violencia, empleando un arma que le ofrecen para intentar suicidarse o intentar matar al interrogador. El recurso a la fuerza condena igualmente a morir al jugador, no es una elección y por ende,no se debe recurrir a ella debido a que es perjudicial. El jugador deberá apreciar todo el abuso sin poder actuar, simplemente podrá preguntarse por qué golpear a un ciudadano obligándolo a confesar como terrorista; el único motivo que encontrará es porque está casado con una mujer palestina.

Este análisis de caso es extenso debido a que es una crítica contra la concepción de seguridad que estuvo vinculada a la guerra del terror (especialmente el uso indiscriminado y sin fundamento de la violencia) a través de la vulneración de los derechos humanos fundamentales. Sin embargo, este juego no agota la capacidad reivindicativa del videojuego ya que se puede encontrar otros que atajan la guerra del terror, especialmente críticos con el empleo de la violencia. 
Estos otros juegos son, por ejemplo September 12th: a toy world (Newsgaming, 2010) y Terrorist Killer (Jordan Magnuson, 2010). Ambos juegos comparten mecánica; el jugador maneja una mirilla (anulando gran parte de la capacidad emocional presente en Langley) y tiene la capacidad de disparar o no. En el primero, el terrorista será identificable y mantendrá una estética guerrillera; en el segundo, será una estética al azar. En ambos casos cuando se decida disparar por parte del jugador siempre habrá, lo que George Bush denominó, "bajas colaterales"; en un alarde de lo que Bordieu denominaría luchas de clasificación, una alodoxia desde un juicio crítico y basado en los derechos humanos.

Estos juegos tienen su gameplay (segundo nivel ideológico de Frasca) diseñado para transmitir la idea de que la violencia, si se emplea, siempre se reproducirá; en ningún caso se podrá, independientemente de los reflejos del jugador, no eliminar algún civil y esto tendrá consecuencias; la "creación" de más terroristas sin poder explicar cómo los servicios de inteligencia y la muerte de más civiles. ¿La moraleja ideológica? El empleo de la fuerza (violencia) generará mayor violencia haciendo imposible completar el juego (la guerra) satisfactoriamente.

No se puede dejar pasar el hecho de que estos juegos se sitúan en un contexto de la guerra del terror. La invasión de Afganistán fue propicia a que se generase un consenso tácito; el modelo de indexado actuó en los grandes medios en buena medida ya que la élite política estadounidense se mostró unánime y no fue hasta que terminó el contexto post 11-S cuando se empezaron a visibilizar las primeras críticas a través de expresiones culturales emanadas de la sociedad, lo que da pie a pensar críticamente sobre el papel de los medios en los conflictos y la desaparición de las expresiones críticas. En este caso, los videojuegos actuaron como un espejo de la sociedad crítica que no encontraba cajas de resonancia en otros espacios comunicacionales.

\section{Discusión y conclusiones}

A raíz de los estudios de caso analizados a lo largo de este texto se puede apreciar que el videojuego actúa como un medio de comunicación fundamental en el ecosistema digital. El elemento videolúdico presenta una capacidad única para transmitir mensajes como ya se ha presentado en otros estudios, debido a que siempre tendrá una ideología subyacente derivado del mensaje buscado por el desarrollador o propio de la interpretación del jugador (Suárez, 2021: 37-54) todo ello porque se desarrolla en un entorno no neutral (García, 2019: 15-36). Para Bogost, esta capacidad de transmisión del mensaje radica en la capacidad de representar el funcionamiento de sistemas reales e imaginarios, lo que permite que el jugador interactúe con ellos y genere juicios (2007).

Lo que los casos analizados transmiten es un contexto, una realidad social que se extendió durante toda la guerra del terrorismo. El atentado del 11 de septiembre actuó como una ventana de oportunidad para aplicar una política exterior concreta pero que, debido al impacto que tuvo, encontró un contexto en el que se había instaurado el modelo del indexado; olvidándose el mainstream de las implicaciones interiores y la estereotipación del "otro". Eso es algo que los datos muestran como por ejemplo, el aumento de los episodios de islamofobia, que solo de 2000 a 2001 aumentaron en un 1554\% en suelo estadounidense (Mars, 2017). Lo que se menciona en el párrafo anterior se traduce en el establecimiento de un preceden- 
te para las relaciones internacionales, al legitimar el uso de la fuerza pero peor fue para las relaciones intercomunitarias, que se pervirtieron a base, principalmente, en estereotipos y la (des)información; El juicio crítico no encontraba cajas de resonancia amplias como para tener repercusión, por eso, se optó en buena medida por el formato videolúdico, algo que se ha explotado en mayor medida con el crecimiento de la industria y la "democratización" de motores gráficos.

Esta generación de juicios críticos sobre la política exterior de los estudios de caso analizados en el presente texto se contrapone a la tendencia mainstream del videojuego que, por ejemplo estudia Bos. En su obra defiende que "[...] the significance of the relationship between videogames and the military, and the particular (geo)political narratives and ideology that are embedded in these virtual worlds, the players themselves have been overlooked" (Bos, 2015). Sin embargo, en sus estudios hace especial hincapié a algo que se ha intentado poner de manifiesto a lo largo de este texto, para estos videojuegos críticos es necesario implicar el elemento emocional en el análisis ya que este resulta fundamental para la comprensión del mensaje; "is also important to recognise the affective capacity of these virtual worlds" (Bos, 2015).

Esta idea de Bos tiene eco en la literatura; por ejemplo, Venegas realiza un exhaustivo análisis sobre los mensajes que transmiten videojuegos mainstream (Call of Duty Modern Warfare), especialmente en un aspecto militarizado, caracterizándolos por la presencia de un avatar poderoso que se enfrenta a enemigos sin la existencia de civiles, lo que se traduce en que no puedan darse violaciones de los derechos humanos al desarrollarse una guerra limpia, con altos índices de tecnología y, enemigos presentados únicamente como tales (Venegas, 2020b; Venegas, 2021: 181-198 ).

Como se ha indicado, a través de sus mecánicas y texto, Langley tiene la capacidad de transmitir los elementos fundamentales de la ideología neoconservadora; Según Iglesias (2017) el sustrato filosófico sobre el que se asienta el neoconservadurismo que dirigió la política americana durante la época de Bush se asienta en que el relativismo moral genera una debilidad; algo que como se indicó, se presenta en el juego como un argumento contra la administración anterior por "no preocuparse", pudiendo haber evitado el 11-S si se hubiese tenido bajo custodia a Bin Laden.

Se ridiculiza en este juego el mensaje de que la tortura es un instrumento válido; como se presentó en los resultados del informe elaborado por el Comité selecto del Senado para el Estudio del programa de detención de la CIA (2014), este informe es en buena medida el contexto del que se nutre el juego mostrando la percepción de la realidad.

La fuerza se suscribe en un mundo donde el sistema internacional se caracteriza por la anarquía y Estados díscolos: solo EEUU puede proveer la seguridad mediante la unipolaridad. Se mezcla un realismo agresivo con valores como la democratización (idealizada) y por la fuerza de oriente medio era una idea que ya se había comenzado a perfilar durante la década de los 90. Esta idea de fuerza es claramente satirizada en el resto de estudios de caso, donde el hecho de emplearla sólo producirá más muerte (y terroristas).

Que todos los juegos mencionados no gocen de un gran presupuesto muestra que se constituyen como una respuesta más "social" y, al estar desprovista de mayores intereses 
pueden permitirse una mayor subversión de las normas. En un estudio de similar índole, Moreno analiza Raid Gaza (2008) cuyo fin es denunciar los bombardeos masivos israelíes sobre gaza mediante la conversión en ejecutor para denunciar las ejecuciones; "La mecánica subvertida se consigue cuando Richert nos convierte en el ejecutor para denunciar la situación del ejecutado" (Moreno, 2019). Este autor ha sido prolífico en este aspecto al tratar a través de una serie de videojuegos de relativo bajo presupuesto la limpieza étnica de los rohingya; la crisis de Sudán, el genocidio de Ruanda o los niños soldado de Uganda (Moreno y Venegas, 2020b).

Pero las denuncias realizadas a través del videojuego no solo agotan aspectos que afectan a los derechos más generales como podría ser la dignidad, la vida, la igualdad, la libertad entre otros que se extraen de nuestros estudios de casos y los estudios de otros autores ya presentados. Por una parte, la explotación infantil como aparece en el caso de Global Conflicts: Sweatshops (Serious Games Interactive, 2009) donde se presentará el cleavage centro periferia a la vez que se construye el derecho a la infancia sobre dilemas morales; te obligará a decidir entre cerrar la fábrica por la explotación infantil que se realiza o bien, permitirla (GamesIndustry International, 2009). Otro ejemplo sería la denuncia de la falta de libertad de prensa y los derechos humanos en Azerbaiyán a través de Real Baku (International Federation of Human Rights, 2015).

Como bien indican los casos analizados en esta discusión y, como se aprecia en nuestro texto, existen juegos creados "ad hoc" para denunciar una situación concreta de acuerdo a la agenda de sus desarrolladores y que siempre estará influida por el contexto en el que se desarrolla; ya sea cultural o temporal. El videojuego está enmarcado en lo que se ha denominado "cultura pop" permitiendo que se produzca una mútua retroalimentación narrativa y estética con otros productos de esta índole. Pero, los videojuegos como experiencia mediada son un formato único a través del que denunciar violaciones de los DDHH y fomentar el juicio crítico. ¿Hasta qué punto se podrá defender el uso de la tortura si hemos logrado empatizar con un personaje que la ha sufrido?

\section{Referencias Bibliográficas}

[1] Bogost, I. (2007). Persuasive Games. The expressive power of videogames. The MIT Press.

[2] Bordón, E. I. (16-18 de octubre, 2019). Experiencia de alfabetización mediática: La televisión y los videojuegos. [Comunicación en congreso].XXI Congreso de la Red de Carreras de Comunicación Social y Periodismo, Facultad de Humanidades (UNSa), Salta.

[3] Bos, D. (2015). Military videogames, geopolitics and methods. En F. Caso y C. Hamilton (Eds), Popular culture and world politics. Theories, Methods, Pedagogies. (101-109). E-International relations publishing.

[4] Bleiker,R. (2001). The Aesthetic Turn in International Political Theory. Millennium- Journal of International Studies, 30 (3). 509-533. DOI: 10.1177/03058298010300031001. 
[5] Elias, C. (2018). Fakenews, poder y periodismo en la era de la posverdad y "hechos alternativos". Ámbitos: Revista internacional de comunicación, (40). Fakenews, poder y periodismo en la era de la posverdad y "hechos alternativos" - Dialnet (unirioja.es)

[6] Frasca, G. (2004). Simulation versus narrative: introduction to ludology. En Wolf (Ed.), The video game theory reader (pp 221-235). Routledge.

[7] Games Industry International (11 de noviembre, 2009). Global Conflicts: Sweatshops. 3D RPG highlighting the 4.9 million 5-to 14-years-olds working in Bangladesh. gamesindustry. biz. Global Conflicts: Sweatshops / GamesIndustry.biz

[8] García, R. (2019). Reflejo de las ideologías a través de las mecánicas. En A.C. Moreno y S. Gómez-García (Eds), Videojuegos del presente. La realidad en formato lúdico.(15-36). TREA.

[9] Gómez, S. y Carrillo, J. A. (2020). El discurso de los newsgames frente a las noticias falsas y la desinformación: cultura mediática y alfabetización digital. Juegos y Gamificación para el desarrollo social y comunitario, (30), 22-46.

[10] Gobierno de España (24 de marzo, 2021). Plan España Hun Audiovisual de Europa. Disponible en: plan-de-impulso-al-sector-audiovisual.pdf (mineco.gob.es)

[11] González, R. (03 de octubre, 2021) La biblioteca sin censura: cómo saltarse el control de las dictaduras en internet a través de un videojuego. El País. La biblioteca sin censura: cómo saltarse el control de las dictaduras en internet a través de un videojuego | Cultura | EL PAÍS (elpais.com)

[12] Ibáñez, J. (2015).Socialconstructivismo: Ideas, valores y normas en la política mundial. En C. Arenal y J. A. Sanahuja (Eds), Teorías de las Relaciones Internacionales (189-218). Tecnos.

[13] ICEX (2019). Polonia, líder regional en el mercado de videojuegos. ICEX.Polonia, líder regional en el mercado de videojuegos (icex.es)

[14] Iglesias, M. (2017). Aznar y los "neocons": el impato del neoconservadurismo en la política exterior de España. Huygens Editorial.

[15] Ley Orgánica Boletín 3/2020, de 29 de diciembre por la que se modifica la Ley Orgánica 2/2006, de 3 de mayo, de Educación. (BOE núm. 340, de 30 de diciembre de 2020)

[16] Ministry of Digital Development, Communications and Mass Media of the Russian Federation [Minkomsvyaz], 2015).

[17] Mainer Blanco, B. y Martínez-Fresneda Osorio, H. (2019). Posverdad y desinformación en la era de los nuevos formatos. Historia y Comunicación Social. 24, (2) , 547-559. DOI:https://doi.org/10.5209/hics.66299. 
[18] Manovich, L. (2005). El lenguaje de los nuevos medios de comunicación. Paidós.

[19] Mars, A. (14 de noviembre, 2017). Aumentan en EEUU los delitos de odio contra musulmanes y latinos. EI País. Aumentan en EE UU los delitos de odio contra musulmanes y latinos | Estados Unidos | EL PAÍS (elpais.com)

[20] McEnchroe,T. y Horáček, J. (09 de octubre, 2021). Culture Ministry considers supporting Czech video game industry. Radio Prague International. Culture Ministry considers supporting Czech video game industry | Radio Prague International

[21] Méndez, R. (2021). Realismo social y metáforas fantásticas. En A.C. Moreno y S. Gómez-García (Eds), Videojuegos del presente. La realidad en formato lúdico.(79-106). TREA.

[22] Moreno, A. C. y Lago, H. (2019). La educación en valores en el aula de Secundaria a través del videjuego Life is Strange. Comunicación y Pedagogía, (313-314). comunicacion y pedagogia 313314 videojuegos en el aula (centrocp.com)

[23] Moreno, A. C. (31 de diciembre, 2019). Mecánicas radicales como crítica política: las creaciones de Raitendo. Presura. Mecánicas radicales como crítica política: Las creaciones de Raitendo (presura.es)

[24] Moreno, A.C. (2020). El estudio de la problemática internacional a través de la serie de videojuegos Global Conflicts. En G. Paredes Otero (Ed.), Comunicación y videojuegos. Reflejando la sociedad a través del ocio interactivo (pp. 15-32). Sevilla: Egregius.idUS - El estudio de la problemática internacional a través de la serie de videojuegos Global Conflicts

[25] Moreno, A. C. y Venegas, A. (2020a). El videojuego como espejo de la sociedad contemporánea. Barataria, Revista Castellano-Manchega de Ciencias Sociales, (29), 1-8. DOI: https://doi.org/10.20932/barataria.v0i29.577

[26] Moreno, A. C. y Venegas, A. (2020b). Videojuegos y conflictos internacionales. Héroes de Papel Studies.

[27] Moreno, C. (2021). Un modelo de análisis político comparado para videojuegos de simulación de gobierno. Estudio de caso con 'Frostpunk', Tropico IV' y 'Civilization V'. index. comunicación, 11(2), 257-281. https://doi.org/10.33732/ixc/11/02Unmode

[28] Newzoo (09 de enero, 2021). Newzoo's Gamer Segmentation: The community of Gamer Explained. Newzoo. Newzoo's Gamer Segmentation: The Community Gamer Explained | Newzoo

[29] Pérez, O. (2012). El lenguaje videolúdico. Análisis de la significación del videojuego. Laertes.

[30] Rojas, C.F. (22-23 de mayo, 2017) Los videojuegos como medio para nuevas estra- 
tegias de gestión urbana. [Comunicación en congreso]. GKA. Congreso Internacional de Cultura Visual, Barcelona.Rojas Zapata (eagora.org)

[31] Sartori, G. (1998). Homo videns La sociedad teledirigida. Taurus.

[32] Scolari, C. (2018). Alfabetismo transmedia en la nueva ecología de los medios. TL_ whit es.pdf (upf.edu)

[33] Senate Select Committee on Intelligence (2014) Committe Study of the Central Intelligence Agency's Detention and Interrogation Program. D87288C34A6D9FF736F9459ABCF83210.sscistudy1.pdf (senate.gov)

[34] Speiser, M. (12 de junio, 2015). The European Games just began, and this video game makes the host country look terrible. Business Insider. This Video Game Protests Against Human Rights Abuses in Azerbaijan (businessinsider.com)

[35] Suárez, A. (2021). El videojuego como transmisor de ideas sociales y políticas. En A.C. Moreno y S. Gómez-García (Eds), Videojuegos del presente. La realidad en formato lúdico. (37-54). TREA

[36] Usher, N. (2019). Alfabetización digital y el futuro del periodismo. Comunicación y Medios, (40). 216-225. Vista de Alfabetización digital y el futuro del periodismo (uchile.cl)

[37] Venegas, A. (21 de enero, 2018): El espectáculo ha desterrado al contexto del videojuego, Presura. El espectáculo ha desterrado al contexto del videojuego (presura.es)

[38] Venegas, A. (12 de octubre, 2020a). La ultraderecha y el videojuego: usos e imágenes, Presura. La ultraderecha y el videojuego: usos políticos y representaciones (presura. es)

[39] Venegas, A. (21 de marzo,2020b). La nueva guerra fría del videojuego: nuevos conflictos y nuevas formas de hacer la guerra, Presura.

https://www.presura.es/blog/2020/03/21/la-nueva-querra-fria-del-videojuego-nuevos-conflictos-y-nuevas-formas-de-hacer-la-guerral

[40] Venegas, A. (2021). El papel del videojuego de guerra en las relaciones internacionales. En A.C. Moreno y S. Gómez-García (Eds), Videojuegos del presente. La realidad en formato lúdico.(181-198). TREA. 


\section{Ludografía}

Beholder Saga (Warm Lamp Games, 2016 - )

Global Conflicts: Sweatshops (Serious Games Interactive, 2009)

Karen Simulator: Wagecuck vs Karen (2GenPro,2020)

Langley (Pixel Chronicles, 2015)

Papers Please (Lucas Pope, 2013)

Raid Gaza (Richter, 2008)

Real Baku (International Federation of Human Rights, 2015)

September 12th: a toy world (Newsgaming, 2010)

Terrorist Killer (Jordan Magnuson, 2010)

\section{CURRICULUM VITAE. JOSÉ ANTONIO MOYA MARTÍNEZ}

Graduado en Ciencias Políticas y de la Administración por la Universidad Complutense de Madrid. Politólogo e investigador. Sus campos de estudio son, principalmente, la problemática internacional a través de los videojuegos, el análisis político y la comunicación política. 